\title{
The evaluation of patients with essential thrombocythemia in terms of risk of thrombosis
}

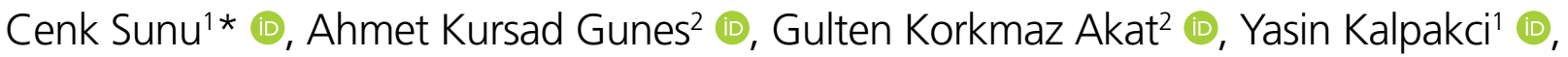 \\ Funda Ceran² (1), Simten Dagdas² (1), Gulsum Ozet² (1)
}

\section{SUMMARY}

OBJECTIVE: The aim of this study was to compare the incidence of factors associated with an increased risk of thrombosis in patients with essential thrombocythemia.

METHODS: A total of 200 patients followed-up in our unit with a diagnosis of essential thrombocythemia in 13 years were analyzed retrospectively.

RESULTS: Of the study participants, $60.5 \%$ were females and $39.5 \%$ were males, with an overall mean $( \pm$ SD) age of 54.93 ( \pm 14.21 ) years. In 119 patients, Janus Kinase 2 was positive with $56.3 \%$ of cases. When two patient categories were defined as those with or without history of thrombosis, no significant differences were found in terms of Janus Kinase 2 positivity, mean age, as well as white blood cells and platelet counts ( $p>0.05$ ). Also, no significant differences in thrombotic event incidence were found between patient categories defined on the basis of cut-off values for white blood cells (cut-off values of $15 \times 10^{3} / \mathrm{mm}^{3}$ and $8.7 \times 10^{3} / \mathrm{mm}^{3}$ ) and platelets (cut-off values of $\left.1500 \times 10^{3} / \mathrm{mm}^{3}\right)(p>0.05)$.

CONCLUSION: Although our results are generally in line with the published data, some divergence from previous results has been observed with respect to risk factors for thrombotic events. Absence of a correlation between leukocytosis and thrombosis may be related with the significant decline in white blood cells after treatment. Also, a significant reduction in platelet counts occurring in association with treatment is linked with a lowered incidence of thrombosis. Janus Kinase 2-positive patients had a similar thrombosis frequency with that reported in the literature.

KEYWORDS: Thrombocythemia, essential. Janus kinase 2. White blood cell count. Platelets. Thrombosis.

\section{INTRODUCTION}

Essential thrombocythemia (ET) is a clonal stem cell disorder that is characterized by isolated thrombocytosis and thromboembolic complications, and it exhibits phenotypic and pathogenetic resemblance with other myeloproliferative neoplasms (MPNs), particularly with polycythemia vera (PV) and primary myelofibrosis (PMF). Our knowledge on the pathogenesis of this disorder remained relatively limited until 2005, when acquired JAK2 mutations were reported in approximately
$50 \%$ of ET patients and in great majority of PMF patients ${ }^{1,2}$. Nearly $55 \%$ of ET patients have JAK2V617F mutations, while JAK2 exon 12 mutations are rare ${ }^{3}$. MPL mutations are seen in approximately $4 \%$ of ET patients ${ }^{4}$. MPL mutations cluster at exon 10, most frequently at MPL W515LVK5. Presence of JAK2 mutations has been associated with an increased risk of arterial thrombosis and lower post-ET MF risk in ET patients ${ }^{6}$.

Several parameters have been used to distinguish higher risk groups from lower risk groups among ET patients, and these

\footnotetext{
'Sakarya University Training and Research Hospital, Department of Hematology - Sakarya, Turkey.

${ }^{2}$ Ankara City Hospital, Department of Hematology - Ankara, Turkey.

*Corresponding author: sunucenk@gmail.com

Conflicts of interest: the authors declare there are no conflicts of interest. Funding: none.

Received on November 05, 2020. Accepted on November 05, 2020.
} 
include age, white blood cells (WBC) count, platelet count, and history of thrombosis ${ }^{7}$. An increased incidence of thrombotic events has been reported in patients over 60 years of age and/or in those with leukocytosis and thrombocytosis. ${ }^{8,9,10}$ JAK2 mutations have been associated with an increased risk of thrombosis, and JAK2 homozygous status was found to increase the risk of vascular complications ${ }^{11,12}$.

This study was undertaken to compare the frequency of factors associated with an increased risk of thrombosis in ET patients.

\section{METHODS}

\section{Selection of study patients}

This retrospective study was undertaken with the participation of 200 patients followed-up and treated with a diagnosis of ET between 2000 and 2013 at the Hematology Unit, Ankara Research and Training Hospital, Turkey. Hemoglobin ( $\mathrm{Hb}), \mathrm{WBC}$, platelet, and cytogenetic test results at baseline (pre-treatment) were recorded. At the last assessment time-point (post-treatment), Hb, WBC, and platelets were remeasured. Age, gender, and history of thrombosis and/or bleeding were also recorded in the case data form.

\section{Statistical analysis}

All the data obtained throughout this study were analyzed using "Statistical Package for the Social Science" (SPSS) version 11.5 for Windows. Descriptive statistics were expressed as frequency, percent distribution, and median values (minmax). Pre- and post-treatment complete blood count parameters were compared with Wilcoxon signed-rank test, while the comparison of WBC between those with or without the history of thrombosis was performed with Mann-Whitney $U$ test. Categorical variables were compared with Fisher's exact test and Yates $\chi^{2}$ test. The value $\mathrm{p}<0.05$ was considered statistically significant.

\section{RESULTS}

The mean age of study participants $(n=200)$ was $54.93 \pm 14.21$ years. A total of $39.5 \%$ of the patients were male and $60.5 \%$ female. JAK2 analysis was available for 119 patients. JAK2 results of $56.3 \%$ of patients were positive and $43.7 \%$ negative. Pre-treatment $\mathrm{WBC}, \mathrm{Hb}$, and platelet counts were significantly higher than post-treatment counts $(\mathrm{p}<0.001$, for all comparisons). The comparison of WBC, $\mathrm{Hb}$, and platelet counts measured at different time points was shown in Table 1. A total of $13.5 \%$ of patients had a history of thrombosis, while $1 \%$ had bleeding, and $1.5 \%$ had both thrombosis and bleeding. About $3.5 \%$ of patients had myocardial infarction (MI), $6 \%$ cerebrovascular events (CVE), 1.5\% portal venous thrombosis, $1.5 \%$ deep venous thrombosis (DVT), 18.5\% peripheral arterial thrombus, $0.5 \%$ pulmonary embolism (PTE), 1.5\% GIS bleeding, and $0.5 \%$ had abdominal aortic thrombosis. The frequency of thrombotic events in JAK2-positive patients was similar to that in JAK2 negative patients $(\mathrm{p}=0.540)$. Patients with or without history of thrombosis did not differ significantly in terms of age $(\mathrm{p}=0.125)$ as well as pre-treatment WBC $(\mathrm{p}=0.442)$ and platelet $(\mathrm{p}=0.804)$ counts. Comparison of age, WBC, and platelets between patients with or without thrombosis is shown in Table 2. Also, no statistically significant differences were found between patients with or without a history of thrombosis with respect to patient categories defined on the basis of age $(\mathrm{p}=0.199)$, pretreatment WBC ( $\mathrm{p}=0.121$ for a cut-off value of $15 \times 10^{3} / \mathrm{mm}^{3}$ and $\mathrm{p}=0.357$ for a cut-off value of $8.7 \times 10^{3} / \mathrm{mm}^{3}$ ), and platelet count $(\mathrm{p}=0.508)$. Distribution of patients with or without history of thrombosis with respect to patient categories defined on the basis of age, WBC, and platelet count is shown in Table 3 .

\section{DISCUSSION}

The clinical course of ET is characterized by microcirculatory disorders and increased risk of arterial and venous thrombosis ${ }^{13}$. In this study, our aim was to evaluate the factors that increase the risk of thrombosis as well as the history of thrombosis and/ or bleeding in a sample of ET patients.

Table 1. Comparison of WBC, $\mathrm{Hb}$, and platelet counts measured at different time points.

\begin{tabular}{|c|c|c|c|c|c|c|c|c|c|c|c|}
\hline & \multicolumn{10}{|c|}{ Time points } & \multirow{3}{*}{$p$} \\
\hline & \multicolumn{5}{|c|}{ Pretreatment } & \multicolumn{5}{|c|}{ Posttreatment } & \\
\hline & Mean & SS & Median & Min & Max & Mean & SS & Median & Min & Max & \\
\hline WBC $\left(\times 10^{3} / \mathrm{mm}^{3}\right)$ & 12.6 & 7.7 & 12 & 4.1 & 80.9 & 7.3 & 2.4 & 7.3 & 2.8 & 21.8 & $<0.001$ \\
\hline $\mathrm{Hb}(\mathrm{g} / \mathrm{dL})$ & 13.6 & 2.1 & 13.5 & 7.5 & 18.4 & 12.8 & 1.88 & 12.8 & 7.8 & 17.4 & $<0.001$ \\
\hline Platelet $\left(\times 10^{3} / \mathrm{mm}^{3}\right)$ & 1074 & 446 & 997 & 514 & 4213 & 431 & 154 & 431 & 98 & 1150 & $<0.001$ \\
\hline
\end{tabular}

WBC: white blood cells; Hb: hemoglobin. 
Table 2. Comparison of age, WBC, and platelets between patients with or without thrombosis.

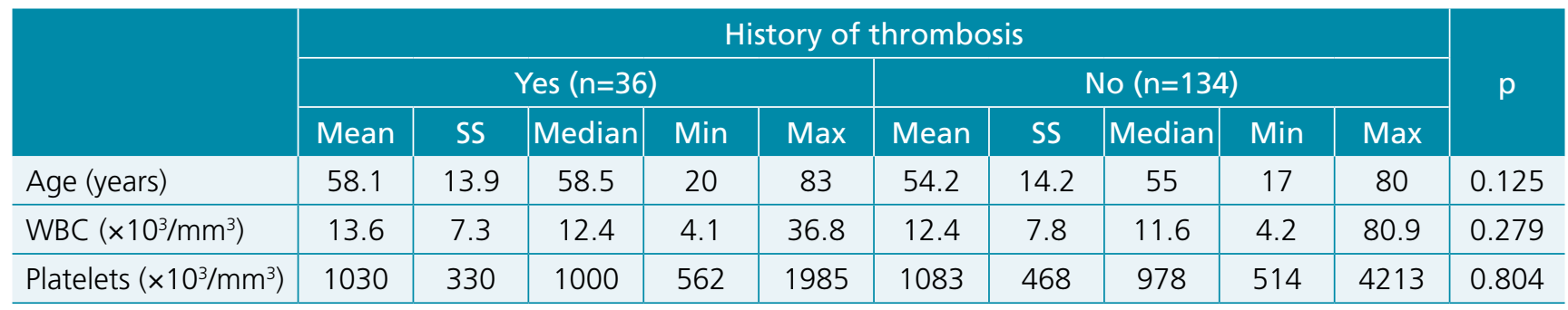

WBC: white blood cells.

Table 3. Distribution of patients with or without history of thrombosis with respect to patient categories defined on the basis of age, WBC, and platelet count.

\begin{tabular}{|c|c|c|c|c|c|c|}
\hline & \multicolumn{4}{|c|}{ History of thrombosis } & \multirow{3}{*}{$\mathrm{p}$} \\
\hline & & \multicolumn{2}{|c|}{ Yes $(n=36)$} & \multicolumn{2}{|c|}{ No $(n=134)$} & \\
\hline & & $\mathrm{n}$ & $\%$ & $\mathrm{n}$ & $\%$ & \\
\hline \multirow{2}{*}{ Age (years) } & $\geq 60$ & 17 & 47.2 & 56 & 34.1 & \multirow{2}{*}{$0.199 *$} \\
\hline & $<60$ & 19 & 52.8 & 108 & 65.9 & \\
\hline \multirow{2}{*}{ WBC $\left(\times 10^{3} / \mathrm{mm}^{3}\right)$} & $\geq 15$ & 10 & 27.8 & 25 & 15.2 & \multirow{2}{*}{$0.121 *$} \\
\hline & $<15$ & 26 & 72.2 & 139 & 84.8 & \\
\hline \multirow{2}{*}{ WBC $\left(\times 10^{3} / \mathrm{mm}^{3}\right)$} & $>8.7$ & 29 & 80.6 & 117 & 71.3 & \multirow{2}{*}{$0.357^{*}$} \\
\hline & $\leq 8.7$ & 7 & 19.4 & 47 & 28.7 & \\
\hline \multirow{2}{*}{ Platelets $\left(\times 10^{3} / \mathrm{mm}^{3}\right)$} & $\geq 150000$ & 3 & 8.3 & 21 & 12.8 & \multirow{2}{*}{$0.580 * *$} \\
\hline & $<150000$ & 33 & 91.7 & 143 & 87.2 & \\
\hline
\end{tabular}

WBC: white blood cells. *Yates $\chi^{2}$ test; **Fisher's exact test.

In a study, the reported rate of JAK2 mutation positivity was $54 \%$, while Duletic et al. reported a positivity rate of $58 \%{ }^{14,15}$. The observed JAK2 positivity rate among our clinical sample was $56.3 \%$.

While $26 \%$ of the ET patients in the study by Duletic et al. had vascular events, the reported rates of hemorrhage and thrombosis in the study by Chou et al. were $18.5 \%$ and $19.2 \%$, respectively, with $2.1 \%$ of the patients having a history of hemorrhage prior to diagnosis ${ }^{14,16}$. In another study, $19 \%$ of the patients had thrombosis and $6 \%$ had bleeding at the time of follow-up, while $4 \%$ of the patients had MI, $4 \%$ had CVE, $1 \%$ had peripheral arterial thrombus formation, $<1 \%$ had PTE, and $3 \%$ had portal venous thrombosis ${ }^{5,17}$. In this study, $13.5 \%$ of the subjects had a history of thrombosis, $1 \%$ had bleeding, and $1.5 \%$ had both thrombosis and bleeding. Also, history of MI, CVE, portal venous thrombosis, DVT, peripheral arterial thrombus formation, abdominal aortic thrombus formation, PTE, and GIS bleeding was present in 3.5, 6, 1.5, 1, 18.5, 0.5, 0.5 , and $1.5 \%$, respectively.

Risk grading systems have been proposed for ET patients to assist in predicting the risk of thrombotic complications ${ }^{18}$.
Risk factors that utilized to define risk categories in ET patients (low, 0 risk factor; high, 1 or 2 risk factors) include age, WBC count, platelet count, and history of thrombosis?

In the multicenter retrospective analysis of Turkish patients, 708 patients who were diagnosed between 1987 and 2014, $55.1 \%$ of all patients had ET. JAK2 mutation was found positive in $51.5 \%$ of patients with ET. At diagnosis, thrombosis was observed in $15.12 \%$ and bleeding occurred in $9 \%$ of ET patients. The incidence of JAK2 mutation, the history of thrombosis, and the median age at diagnosis were lower than in the literature ${ }^{19}$. JAK2 mutation, observed in $50-60 \%$ of patients with ET, has been an independent risk factor for thrombosis, but less is known about the underlying mechanism of this relation ${ }^{20}$. However, in this study, patients with JAK2 positivity did not exhibit a significant increase in thrombotic events as compared with patients who were JAK2 negative. The main limitation of this study is the retrospective and observational data collection techniques, which restricts making causal assumptions.

Advanced age is an important risk factor for thrombosis, with patients over 60 years of age having an increased occurrence of thrombotic events ${ }^{8}$. Although ET patients 
with thrombotic events were slightly older than those without such events, the difference did not reach statistical significance in our study.

Previous research has provided evidence for an increased risk of thrombosis in ET patients with leukocytosis ${ }^{8,9}$. WBC count higher than $8.7 \times 10^{3} / \mathrm{mm}^{3}$ or higher than $15 \times 10^{3} / \mathrm{mm}^{3}$ was proposed to represent an independent risk factor for thrombotic events ${ }^{17}$. Although ET patients with a history of thrombosis had higher WBC counts than those without such a history, the difference was insignificant. Therefore, our results suggest that no associations may be present between thrombotic event frequency and the two separate cut-off values for WBC. The absence of a correlation between leukocytosis and thrombosis may be related to the significant reduction in WBC counts with treatment in our patients. In the last decade, several studies have investigated the association between leukocytosis and risk of thrombosis in patients with MPN, but the conclusions were not univocal. Furthermore, even in studies concluding that leukocytosis was associated with thrombosis, no consensus was found on the numerical cut-off that should be used to define leukocytosis ${ }^{21}$.

Another important consideration in reducing the risk of thrombosis involves the prevention of thrombocytosis ${ }^{22}$. Platelet count of $<1000 \times 10^{3} / \mathrm{mm}^{3}$ in a patient over 60 years of age or a platelet count $\geq 1500 \times 10^{3} / \mathrm{mm}^{3}$ in those less than 60 years of age may be considered an indication for the use of agents that reduce the number of platelets ${ }^{10}$.

The hypercoagulability state is a condition that may induce the thrombosis phenomenon. The markers of this state were identified in patients who received estrogen associated with progestagens. Furthermore, patients who received oral estrogen plus medroxyprogesterone showed a decrease in antithrombin III, which is a risk factor for thrombosis. Therefore, this association may lead to a procoagulant state in ET patients who received estrogen plus medroxyprogesterone ${ }^{23}$. Also, the inflammatory changes are part of coronavirus disease 2019 (COVID-19) pathophysiology and this might generate a higher thromboembolic risk in patients using combined hormonal contraception and menopausal hormone therapy. The thrombosis risk of ET patients affected by COVID-19 using combined hormonal therapy should also be evaluated in this respect ${ }^{24}$.

Our results are in disagreement with the previous reports in terms of the incidence of thrombotic events in patients with leukocytosis, increased platelet count, or JAK2 positivity. The absence of a correlation between leukocytosis and thrombosis may be related to the significant reduction in WBC counts with treatment in our patients. Similarly, significant reductions in platelet counts that achieved by treatment have been associated with reduced frequency of thrombosis. JAK2 mutations could be evaluated in only 119 of our patients due to technical constraints between the years 2000 and 2006. In this regard, the inconsistency between the previous reports and this study in terms of the thrombotic events in JAK2-positive patients may be related with the small sample size.

\section{CONCLUSION}

The thrombo-hemorrhagic events occur in patients with ET. JAK2 mutation, leukocytosis, and thrombocytosis are associated with a high risk of thrombosis. We concluded that the effective control of WBC and platelet counts can reduce the risk of thrombosis.

\section{AUTHORS" CONTRIBUTIONS}

CS: Writing - Review \& Editing. AG: Investigation. GA: Data Curation. YK: Resources. FC: Methodology. SD: Validation. GO: Supervision.

\section{REFERENCES}

1. Campbell PJ, Green AR. The myeloproliferative disorders. N Engl J Med. 2006;355(23):2452-66. https://doi.org/10.1056/ NEJMra063728

2. Takenaka K. Progress in elucidation of molecular pathophysiology and its application in therapeutic decision-making for myeloproliferative neoplasms. Int J Hematol. 2020;111(2):180-1. https://doi.org/10.1007/s12185-019-02812-w

3. Scott LM. The JAK2 exon 12 mutations: a comprehensive review. Am J Hematol. 2011;86(8):668-76. https://doi.org/10.1002/ ajh.22063

4. Pardanani A, Lasho TL, Finke CM, Tefferi A. Infrequent occurrence of MPL exon 10 mutations in polycythemia vera and post-polycythemia vera myelofibrosis. Am J Hematol. 2011;86(8):701-2. https://doi.org/10.1002/ajh.22058
5. Boyd EM, Bench AJ, Goday-Fernández A, Anand S, Vaghela $\mathrm{KJ}$, Beer $\mathrm{P}$ et al. Clinical utility of routine MPL exon 10 analysis in the diagnosis of essential thrombocythaemia and primary myelofibrosis. Br J Haematol. 2010;149(2):250-7. https://doi. org/10.1111/j.1365-2141.2010.08083.x

6. Carobbio A, Thiele J, Passamonti F, Rumi E, Ruggeri M, Rodeghiero F, et al. Risk factors for arterial and venous thrombosis in WHO-defined essential thrombocythemia: an international study of 891 patients. Blood. 2011;117(22):5857-9. https:// doi.org/10.1182/blood-2011-02-339002

7. Passamonti F, Rumi E, Arcaini L, Boveri E, Elena C, Pietra $D$, et al. Prognostic factors for thrombosis, myelofibrosis, and leukemia in essential thrombocythemia: a study of 605 patients. Haematologica. 2008;93(11):1645-51. https://doi. org/10.3324/haematol.13346 
8. Andıç N, Ünübol M, Yağcı E, Akay OM, Yavașoğlu I, Kadıköylü VG, et al. Clinical features of 294 turkish patients with chronic myeloproliferative neoplasms. Turk J Haematol. 2016;33(3):18795. https://doi.org/10.4274/tjh.2015.0041

9. Carobbio A, Finazzi G, Guerini V, Spinelli O, Delaini F, Marchioli $R$, et al. Leukocytosis is a risk factor for thrombosis in essential thrombocythemia: interaction with treatment, standard risk factors, and Jak2 mutation status. Blood. 2007;109(6):2310-3. https://doi.org/10.1182/blood-2006-09-046342

10. Tefferi A, Gangat N, Wolanskyj AP. Management of extreme thrombocytosis in otherwise low-risk essential thrombocythemia; does number matter? Blood. 2006;108(7):2493-4. doi: 10.1182/ blood-2006-05-025544

11. Tefferi A, Thiele J, Orazi A, Kvasnicka HM, Barbui T, Hanson CA, et al. Proposals and rationale for revision of the World Health Organization diagnostic criteria for polycythemia vera, essential thrombocythemia, and primary myelofibrosis: recommendations from an ad hoc international expert panel. Blood. 2007;110(4):1092-7. https:// doi.org/10.1182/blood-2007-04-083501

12. Barbui T, Vannucchi AM, Guglielmelli P, De Stefano V, Rambaldi A. An agenda for future research projects in polycythemia vera and essential thrombocythemia. Haematologica. 2020;105(8):19992003. https://doi.org/10.3324/haematol.2019.246207

13. Frederiksen H, Szépligeti S, Bak M, Ghanima W, Hasselbalch HC, Christiansen CF. Vascular diseases in patients with chronic myeloproliferative neoplasms - impact of comorbidity. Clin Epidemiol. 2019;11:955-67. https://doi.org/10.2147/CLEP.S216787

14. Duletić AN, Dekanić A, Hadzisejdić I, Kusen I, Matusan-llijas $\mathrm{K}$, Grohovac D, et al. JAK2-v617F mutation is associated with clinical and laboratory features of myeloproliferative neoplasms. Coll Antropol. 2012;36(3):859-65. PMID: 23213945

15. Carobbio A, Antonioli E, Guglielmelli P, Vannucchi AM, Delaini F, Guerini $\mathrm{V}$, et al. Leukocytosis and risk stratification assessment in essential thrombocythemia. J Clin Oncol. 2008;26(16):2732-6. https://doi.org/10.1200/JCO.2007.15.3569

16. Chou YS, Gau JP, Yu YB, Pai JT, Hsiao LT, Liu JH, et al. Leukocytosis in polycythemia vera and splenomegaly in essential thrombocythemia are independent risk factors for hemorrhage. Eur J Haematol. 2013;90(3):228-36. https://doi. org/10.1111/ejh.1206
17. Gangat N, Wolanskyj AP, Schwager SM, Hanson CA, Tefferi A. Leukocytosis at diagnosis and the risk of subsequent thrombosis in patients with low-risk essential thrombocythemia and polycythemia vera. Cancer. 2009;115(24):5740-5. https:// doi.org/10.1002/cncr.24664

18. Finazzi $G$, Barbui T. Evidence and expertise in the management of polycythemia vera and essential thrombocythemia. Leukemia. 2008;22(8):1494-502. https://doi.org/10.1038/leu.2008.177

19. Soyer N, Haznedaroğlu iC, Cömert M, Çekdemir D, Yılmaz M, Ünal A, et al. Multicenter retrospective analysis of Turkish patients with chronic myeloproliferative neoplasmsmulticenter retrospective analysis of Turkish patients with chronic myeloproliferative neoplasms. Turk J Haematol. 2017;34(1):2733. https://doi.org/10.4274/tjh.2016.0005

20. Koçak MZ, Daglı M, Fidan K. Assessment of risk factors affecting thrombosis in patients with essential thrombocytosis. J Surg Med. 2018;2(2):46-9. https://doi.org/10.28982/ josam.396881

21. Carobbio A, Ferrari A, Masciulli A, Ghirardi A, Barosi G, Barbui T. Leukocytosis and thrombosis in essential thrombocythemia and polycythemia vera: a systematic review and meta-analysis. Blood Adv. 2019;3(11):1729-37. https://doi.org/10.1182/ bloodadvances.2019000211

22. Dombi P, Illés Á, Demeter J, Homor L, Simon Z, Karadi $E$, et al. Anagrelide reduces thrombotic risk in essential thrombocythaemia vs. hydroxyurea plus aspirin. Eur J Haematol. 2017;98(2):106-11. https://doi.org/10.1111/ ejh.12806

23. Bonduki CE, Lourenço DM, Motta EL, Soares Júnior JM, Haidar MA, Baracat EC. Effect of estrogen-progestin hormonal replacement therapy on blood coagulation and fibrinolysis in postmenopausal women. Clinics (Sao Paulo). 2007;62(5):553-60. https://doi.org/10.1590/s180759322007000500004

24. Pires ALR, Batista JG, Aldrighi JM, Massaia IFDS, Delgado DM, Ferreira-Filho ES, et al. Risk of venous thromboembolism in users of contraception and menopausal hormone therapy during the COVID-19 pandemic. Rev Assoc Med Bras (1992). 2020;66(Suppl 2):22-6. https://doi.org/10.1590/18069282.66.S2.22 